\title{
Puberty and Its Signs According to A Contemporary Islamic Jurisprudential- Legal View
}

\author{
Abdulhakeem Abdulrahman Al-Saadi \\ Department of Jurisprudence and its Foundations, College of Sharia and Islamic Studies, Qatar University, Qatar \\ a.alsaadi@qu.edu.qa
}

KEYWORDS: $\quad$ Puberty, Assignment, Medical Puberty Signs, Puberty in Fiqh, Legal Puberty.

Crossref doi) https://doi.org/10.51345/.v32i4.457.g253

\begin{abstract}
:
Puberty is the subject of assignment, it is known either by the age of a young man or woman, or by signs, some of which were mentioned by jurists through experiences, environment, and so on. Then, in the present era, many issues have arisen that young men and women are going through, which may be a reason for accelerating puberty with a new signs or rate of growth, were unknown by ancient jurists due to the change in the environment, nutrition and moderation of the atmosphere, which causes activation of hormones that accelerate the puberty of the young man or woman. Hence, writing in determining puberty as an age or a sign according to the developments of the age is a matter required by modern studies so that the contemporary fatwa is based on the changes and developments of the age. Consequently, the idea of this research was raised. The research cossets an introduction revealing the importance of determining the age of puberty and how it considered the basis of the assignment where the reference to assignment (understanding the discourse). Whoever reaches the puberty was before that either without understanding during early childhood, or deficient in understanding when he later becomes a child of comprehension. Then I talked about puberty, in terms of jurisprudence, law, and medicine. The research ended up with the conclusion of the most important results of the study. The research was titled (the age of puberty and its signs according to a contemporary jurisprudential-legal view), in which it relied on the most important Islamic Fiqh, legal and medical references.
\end{abstract}




\title{
سن البلوغ برؤية فقهية أصولية قانونية معاصرة
}

\author{
أ.د. عبدالحكيم عبدالرحمن السعدي

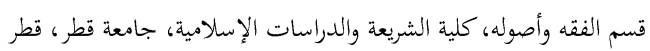 \\ a.alsaadi@qu.edu.qa
}

سن البلوغ، مناط التكليف، علامات البلوغ الطبية، البلوغ في الفقه، البلوغ في القانون.

الكلمات المفتاحية

Crossref doi https://doi.org/10.51345/.v32i4.457.g253

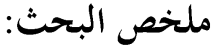

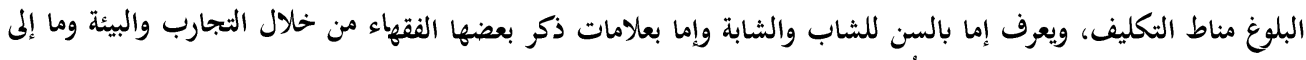

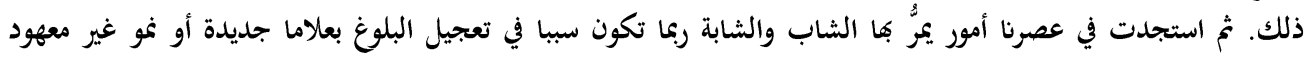

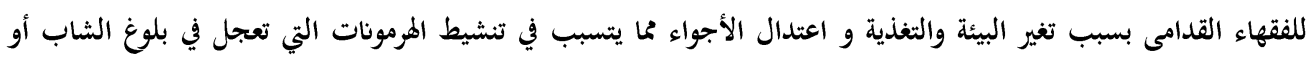

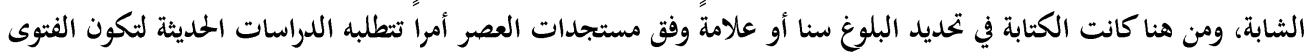

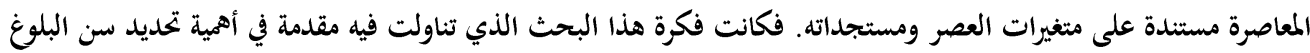

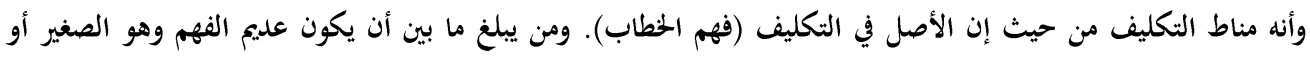

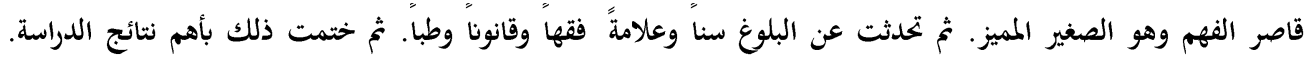

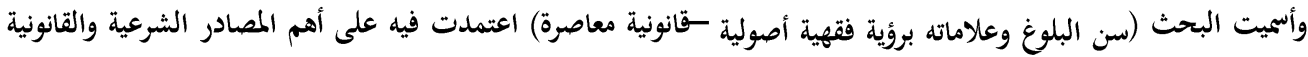

والطبية.

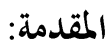

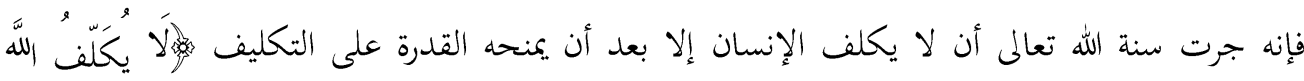

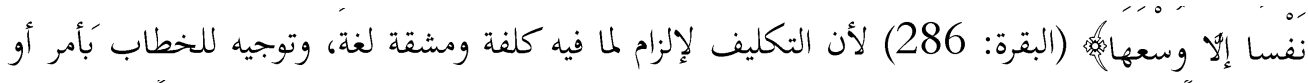

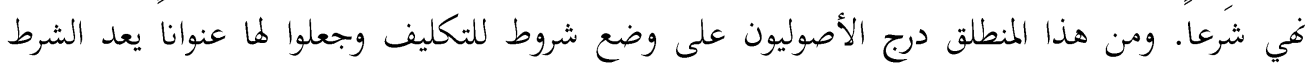
الأساس من شروط التكليف وهو: (القدرة على فهم الخطاب) لتخرج كل العناصر التي لا قدرة لها على فهم الخطاب وهذا شرط متفق عليه بين الأصوليين، نقل الاتفاق عليه الامدي وغيره(1). ونتج عن هذا الشرط أفم اتفقةا على عدم صحة تكليف بعض بني البشر واختلفوا في بعض آنر آخر فقد

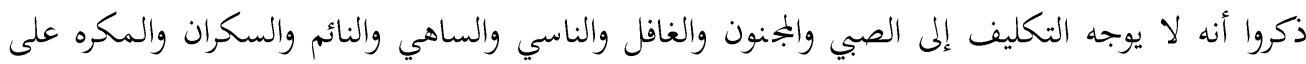
تفصيل كبير في كل عنصر من هذه العناصر التي يجمعها الشرط المذكور وهو عدم فهم الخطاب لكن لماكي كان 
عدم القدرة على فهم الخطاب متفاوتاً بين هذه العناصر ولا مستديماً بحث الأصوليون كلاً على حدة لتحديد تحقق هذا الشرط على وجه الدقة. وقد اتجهت النية إلى تفصيل القول في بحثنا إلى أن نتناول عنصراً من هذه العناصر وهو (الصبي) أو ما يطلق عليه الكثير من الفقهاء (الصغير):

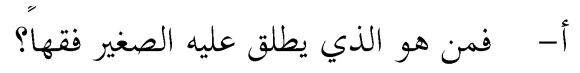
ب- وما أنواعه عند النظر إلى التدرج في سنوات العمر؟

$$
\text { ج- ومتى يصبح بالغاً ليصح تكليفه؟ وهل سن البلوغ هو سن الرشد بعينه؟ }
$$

وسنبحث هذا تحت عنوان: (سن البلوغ فقها وقانونا)، ويتكون من مقدمة وخمس مسائل وخاتمة. 1- المقدمة: لمحة عن أهمية الموضوع وتقسيماته. 2- المسألة الأولى: الصغير - الصبي: تعريفه وأنواعه. 3- المسألة الثانية: تقسيم الصبي إلى ميز وغير مميز، وبيان مراحل الإنسان.

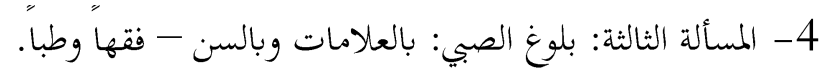

$$
\text { 6- 6- المسألة الرابعة: سن البلوغ قانونا. }
$$

ولابدَّ من الإشارة إلى أننا نبحث في عصر التقدم العلمي والتكنولوجيا المعاصرة وهذا يدعونا إلى أن لا نجمد على آراء الفقهاء القدامى في أمور قد يكون للعلم المعاصر دخل في دقة تحديدها وفهمها، بل لابد من الرجوع إلى علماء العصر من أطباء ومختصين لتحديد أبعاد ذلك بدقة وبالتالي سيأتي الحكم الفقهي الشرعي أقرب إلى الصواب، والله المستعان.

\section{المسألة الأولى: الصغير - الصبي}

هذان المصطلحان لمما مدلولمما المحدد لدى علماء الأصول وهو (الشخص غير البالغ) ذكرأكران أو أنثى، لكن في الأنثى يقال (الصغيرة والصبية) وحين نطلق القول هنا بلفظ المذكر نعني به ما يشمل المذكر والمؤنث

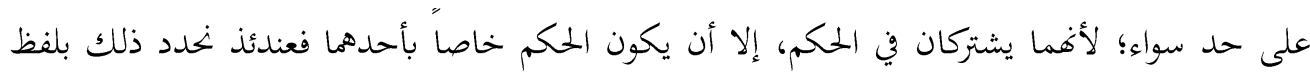
يناسبه من التذكير أو التأنيث.

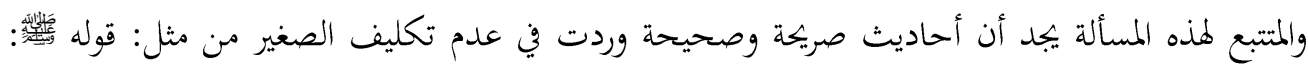
(رفع القلم عن ثلاثة: عن الصبي حتى يبلغ، وعن النائم حتى يستيقظ، وعن المجنون حتى يفيق)(2). ومقتضى 
ظاهر الحديث أن الصبي مطلقاً لا يوجه إليه خطاب التكليف. لكن بالعودة إلى تحليل النص نجد أن رفع

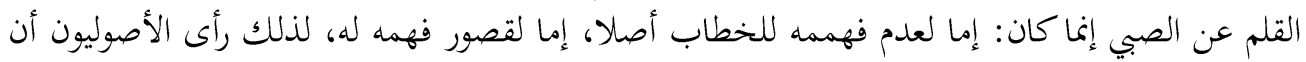
شرط فهم الخطاب لا يتحقق في جميع من يطلق عليه أنه صبي، بل هناك من الصبيان من يستطيع فهم

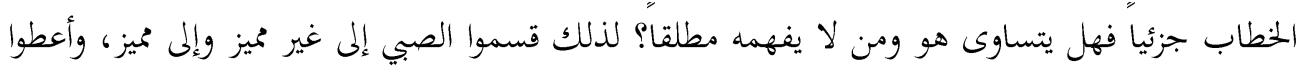
لكل حكمه في التكليف. المسألة الثانية: تقسيم الصبي إلى غير المميز - والصبي المميز

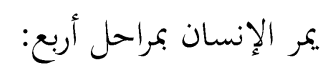
المرحلة الأولى: كونه جنيناً في بطن أمه.

$$
\text { المرحلة الثانية: كونه طفلاَّعقب الولادة (غير ميزيز). }
$$

المرحلة الثالثة: كونه طفلا ميزاً وتبدأ بانتهاء المرحلة الثانية. المرحلة الرابعة: كونه بالغاً وتبدأ بعد انتهاء المرحلة الثالثة.

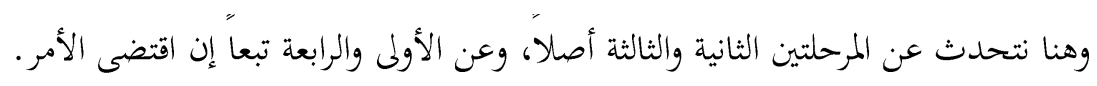

$$
\text { أولاً: الصبي غير المميز: }
$$

بعد أن يولد الإنسان حيا، يتحقق وجوده بعد أن كان وجوده في بطن أمه ظنا، أو على الأقل أن يقال هل

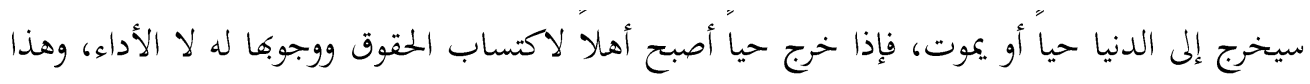
ما يسميه الأصوليون (أهلية الوجوب الكاملة). لكن إلى أي سن تمتد هذه الصلاحية التي يكون الطفل فيها غير مميز؟ اختلف الفقهاء في ذلك: فذهب

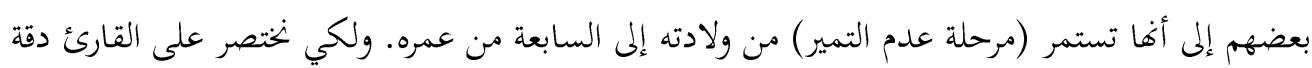

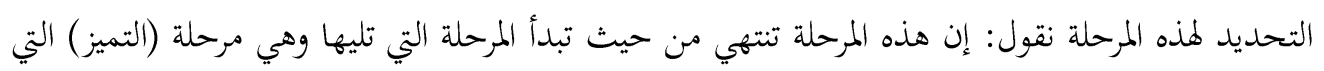
سنرى وجهة نظر الفقاء في تحديدها. التكليف في هذه المرحة (الصبي غير المميز):

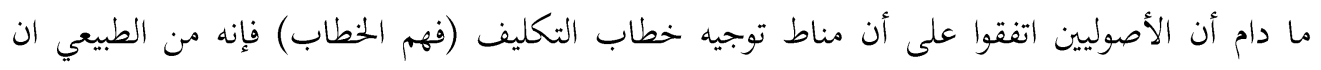

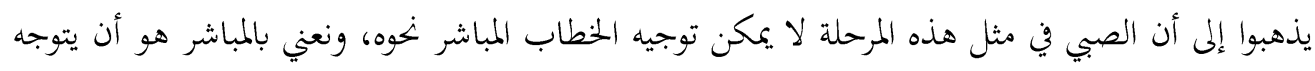

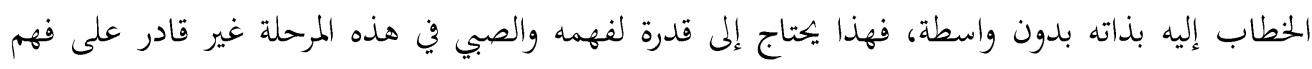

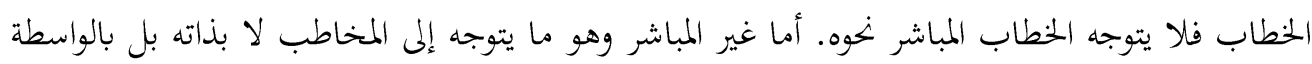


ليكون التكليف خارجا عن أداء المكلف بذاته، بل يكون المكلف به غيره فهذا ضمن ما هو ممكن فلا يمتنع

وعند الرجوع إلى تقسيم الأصوليين أهلية الوجوب التي تعني أن يكون الإنسان أهلا لاكتساب الحقوق له وعليه نجد أفم أناطوا ذلك بخروج الإنسان حيا، ومثل هذا الطفل الحي، يمتلك هذه الإني الأهلية (أهلية الوجوب) كاملة، ويترتب على ذلك أنه:

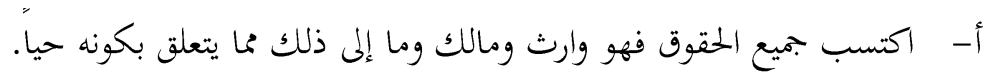

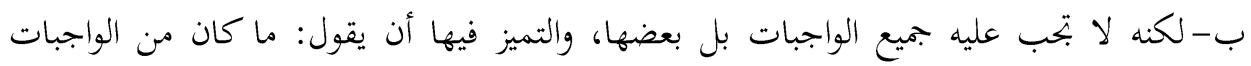
بحاجة إلى قدرة للأداء فإنه غير مكلف به لقصور فهمه وقدرته فلا بحب عليه صلاة ولا صيام ولا حج ولا غير ذلك مما يحتاج إلى قدرة للأداء. وما كان من الواجبات لا يجتاج إلى تلك القدرة فإنه يتوجه الخطاب إليه باعتبار أن من يؤديه عنه قادر

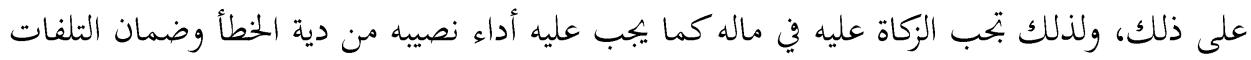
وغير ذلك من الأمور التي يخاطب بها ولي أمره، فهو في هذه الحال: قادر بغيره لا بذاته، وهو ما بيمكن أن يطلق عليه (خطاب الوضع بالتسبب) والتبعات الأخروية لا تكون عليه بذاته بل على ولي أمره إذا

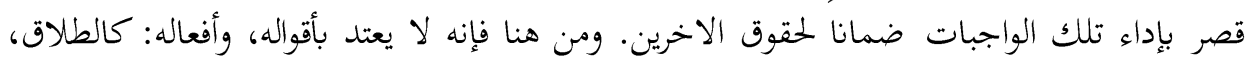

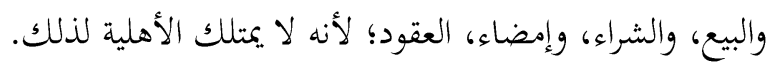$$
\text { ثانيا: الصبي المميز : }
$$

مرحلة التميز تبدأ من حيث انتهت ما قبلها، فجمهور الفقهاء حددوا سن التميز من حين بلوغ الصبي أو

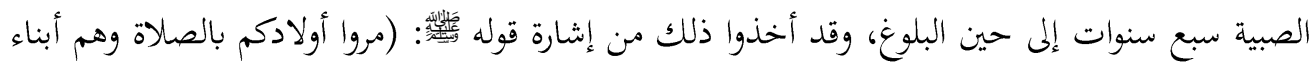

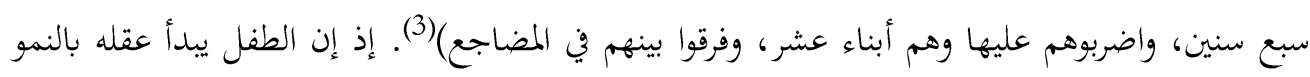

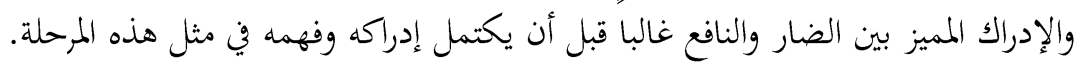

التكليف في هذه المرحة (التميز): ما زال الطفل في هذه المرحلة غير قادر على فهم الخطاب كاملا، ومن هنا لا يتوجه إليه خطاب التكليف،

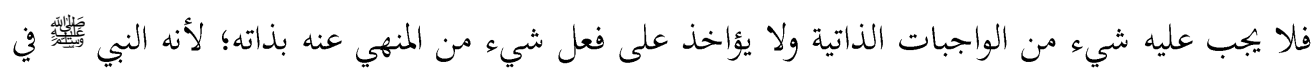
أكثر من حديث له ربط التكليف بالبلوغ، وواضح أن ذلك لقصور فهم ما قبل هذه المرحلة.

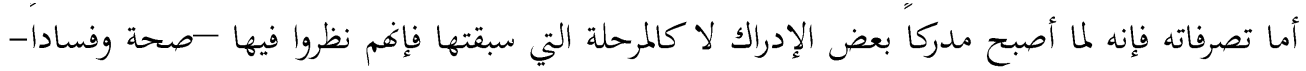

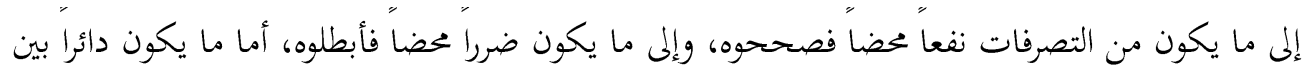


النفع والضرر فجعلوه موقوفا على ذات لي أمره وتقديره. وقد فصل الأصوليون ذلك تفصيلا بديعا ليس هذا مل بسطة) (4)

\section{المسألة الثالثة: بلوغ الصبي - بالعلامات وبالسن فقها وطبا"}

هذه المرحلة هي ما عقدت البحث فيها لتحديد سن البلوغ للصبي والصبية من حيث علاماته وسنه. ولقد عني الفقهاء بهذه المرحلة لأفها مناط التكليف واكتمال أهليه الأداء بعدما اكتملت أهلية الوجوب بوجود الإنسان حيا، وقرورا أن البلوغ يعرف إما بالعلامات وإما بالسن وبينهما فروق بين الذكر والأنتى، كما أغم حددوا ذلك باجتهادات مرد معظمها إلى العرف والتجارب، ونخن في هذا البحث نضيف إلى رأي علماء الطب والطبيعة البشرية ضمن القواعد المعاصرة والتكنولوجيا الحديثة، فنقول:

\section{أولا": علامات البلوغ عن الفقهاء:}

أ- أحنفية قالوا:

يعرف البلوغ عند الذكر بعلامات ثلاث أو أربع:

$$
\text { الأولى: الاحتلامب }
$$

الثانية: إنزال المني باحتلام أو بغيره، ومعروف أن المني هو الماء النازل المتدفق المصحوب بالشهوة. الثالثة: إحبال المرأة، وهذا لا يتضح حتى يقوم بجماعها. الرابعة: ربما أضاف بعضهم إنبات شعر العانة والشوارب وخشونة الصوت. أما في الصبية: فإن البلوغ يعرف فيها بعلامتين: الأولى: الحيض: وسنأتي إلى تفصيل السن الذي يعد الدم اللنارج منها حيضاً أو غيره. الثانية: الحبل: ويعرف فيما إذا جومعت أو دخل مني في فرجها فحدث الحمل فقد بلغت وربما أضاف بعضهم الإنبات.

ويلاحظ هنا على هذه العلامات سواء كانت علامات الذكر أو علامات الأنثى إذا حصل بعضها في أحدهما حكموا عليه بالبلوغ وأصبح مكلفاً مالم يكن هناك مانع عند البلوغ من تكليفه كالجنون مثلاً(5). ب- أما الثافعية: فإهم ذهبوا إلى أن البلوغ بالعلامات يكون في الصبي: بالإمناء وقد أتم الصغير تسع سنين، فإذا أنزل قبل ذلك فإنه ناشيء عن مرض لا عن بلوغ فلا يعد علامة له، ولعلهم حين لم يذكروا الإحبال الذي صرح به الحنفية؛ لأنه لا يمكن الإحبال مالم يحدث الإنزال للمني. 


\section{ويكون في الصبية:}

في الحيض في أي مرحلة عمرية حدث، لكن ينبغي التأكد من كون الدم النازل دم حيض لا نزفا نتيجة

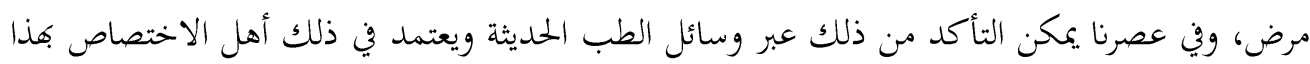
الشأن والتحليلات المخبرية. ولم يذكر الشافعية علامات أخرى كالتي ذكرها غيرهم لبلوغ الصبية(6).

\section{ج- أما الحنابلة:}

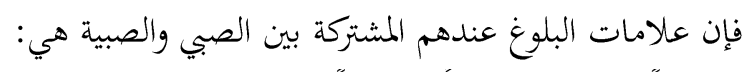

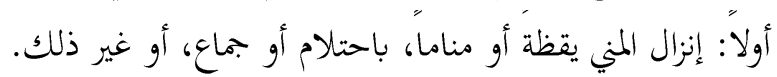

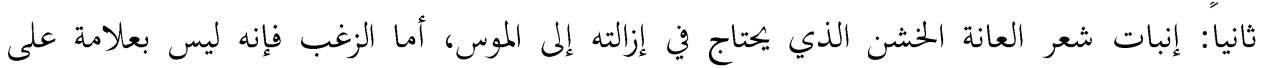
البلوغ؛ لأنه قد يحصل للأطفال. وتزيد الصبية علامات أخرى غختصة بها لا تكون للصبي وهي:

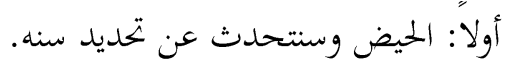

$$
\begin{aligned}
& \text { ثانيا: الحبل بأي طريقة حدث الحيض وستحث عن تخديل }
\end{aligned}
$$

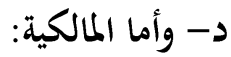

فإن علامات البلوغ عندهم ما يأتي:

أولاً: إنزال المني مطلقاً في اليقظة أو الحلم، وهذا يمكن مأن أن يكون مشتكاً بين الصبي والصبية.

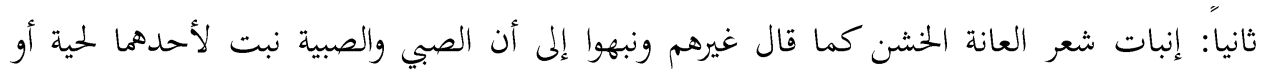

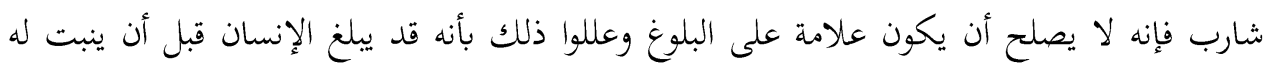

$$
\begin{aligned}
& \text { ذلك. } \\
& \text { ثالثا: نتف الإبط. } \\
& \text { رابعاً: فرق أرنبة الأنف. لإبط. }
\end{aligned}
$$

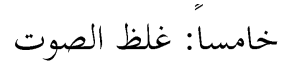

وهذه الأوصاف الثلاثة الأخيرة مشتركة بين الصبي والصبية إلا أنني لا أراها منضبطة، ولا علامة على البلوغ إلا نادراً إلا أن تصحبها علامة أخرى مما قال به غير الاخيرة مثتركه بين المالكية. سادساً: الحيض، وسيأتي تحديده. سابعا: الحبل. وهما خاصان بالصبية(8) 


\section{خلاصة علامات البلوغ لدى الفقهاء:}

يمكن تلخيص علامات البلوغ لدى الفقهاء بالآتي:

أولا: العلامات المشتركة بين الصبي والصبية:

1- إنزال المني، به قال فقهاء المذاهب كلهم، ويشمل إنزاله بالاحتلام أو بغيره.

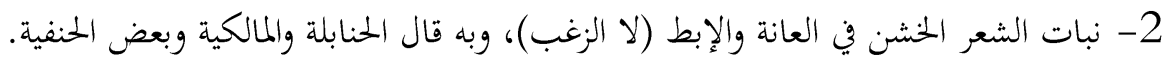

3- نتف الإبط.

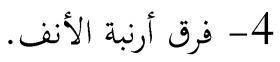

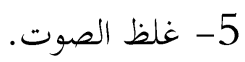

وهذه الأوصاف الثلاثة الأخيرة قال بها المالكية. ثانيا: العلامات الخاصة بالصبي:

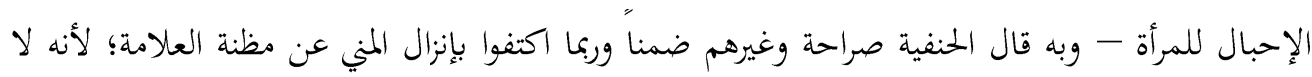
يجدث الإحبال من غير إنزال للمني. ثالثا: العلامات الخاصة بالصبية: 1 - الحيض، وسنتحدث عن سنه.

2- الحبل، وهو ما صرح به الحنفية والمالكية والحنابلة.

ويلاحظ كما أشرنا إلى أن بعضها ذكره الفقهاء صراحة وهي لوضوحها لا تحتاج إلى بيان، وبعضها يتدال مع علامات أخرى بالتلازم، فهي أقرب إلى أن يكون بعضها نتيجة للأخرى ولا تحتاج إلى تحديد سن لئن معينة، لكن الحيض يحتاج إلى سنة وهذا ما سنتناوله بالآتي:

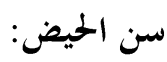

الحيض الذي قال به جميع الفقهاء أنه علامة على بلوغ الصبية وقع خلاف في تحديده؛ لأنه إذا كان الدم

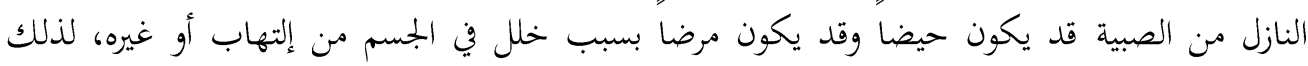

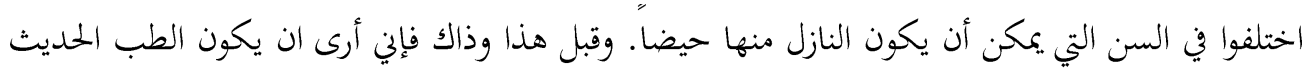

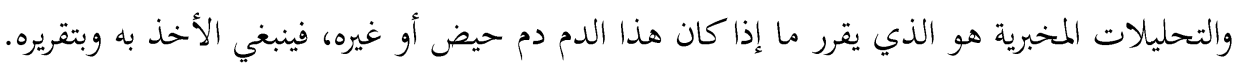
أما الفقهاء القدامى فقد قالوا في سن الحيض: 


\section{أ- الحنفية:}

فمحمد بن مقاتل الرازي -رحمه الله- يرى أن الدم الذي يعد حيضا ويهكم به بالبلوغ هو إذا بلغت تسع

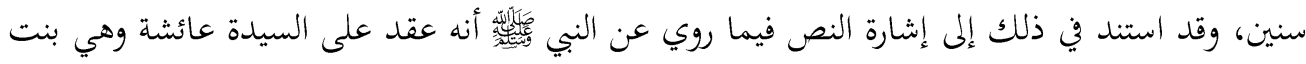
ست سنوات وبنى به -أي: دخل- وهي بنت تسع سنوات(9) ويبدو أن الدخول كان بعد البلوغ.

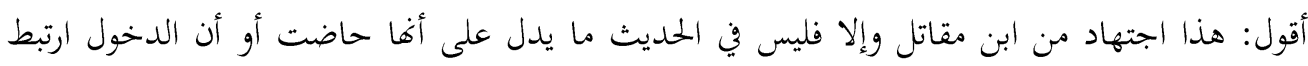

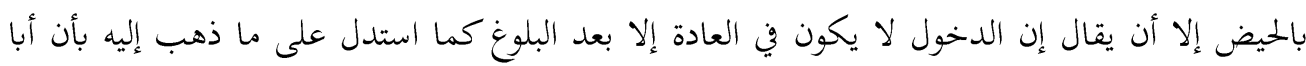
مطيع البلخي كانت له بنية صارت جدة وهي بنت تسع عشرة سنة وكان أبو مطيع يقول: (فضحتنا هذه

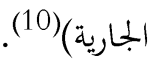

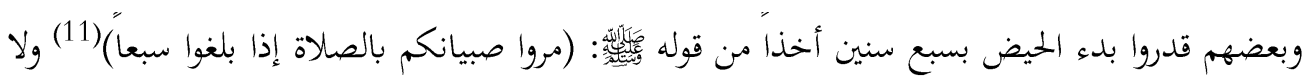
وجوب إلا بعد البلوغ.

وبعضهم قدره بست سنوات، فقد سئل أبو نصر محمد بن محمد بن سلام البلخي: عن بنت ست سنين

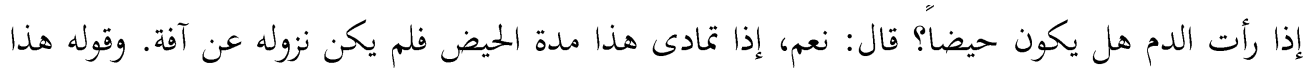

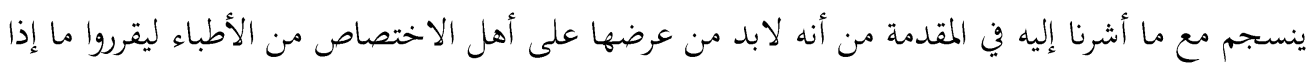
كان هذا الدم دم حيض أو غير ذلك. وبعضهم قدره باثنتي عشرة سنة، فقالوا: الأغلب الأعم في زماننا رؤية الدم في ثلاثة عشر سنة أو في أربع دأ دأ

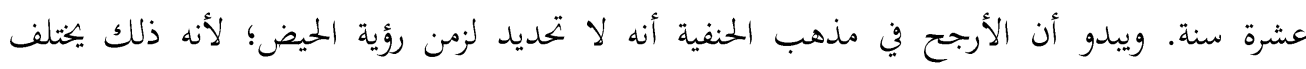
باختلاف البلدان وطبيعة الجو من حرارة وبرودة، فيترك الأمر لطبيعة وجود البنت والعرف في ذلك المكان المكان بالاستعانة بسؤال أهل الاختصاص أو الخبرة(12).

\section{ب- الشافعية:}

ربط إمام الحرمين الجويني سن الحيض بسن البلوغ ناقلا عن الإمام الشافعي أن بلوغ الغلام ممكن بعد مضي لفي

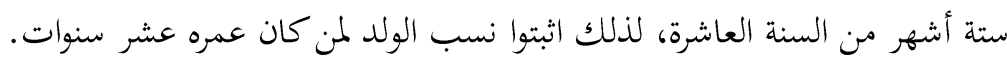
ثم ذكر الجويني: إن من أصحابنا من يقول: يدخل إمكان البلوغ الغلام في السنة العاشرة، وأما الجارية فإنه

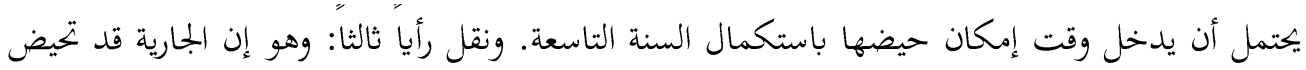

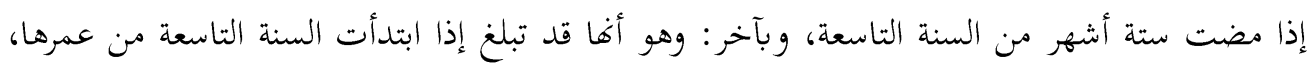
فهي أسرع بلوغاً من الغلام. 
وأعقب ذلك بقوله: (إنما يتفق ما ذكرناه في البلاد الحارة). ثم ختم كل ذلك برأي لظاهر المذهب: ملخصه

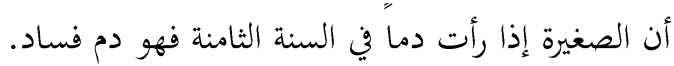

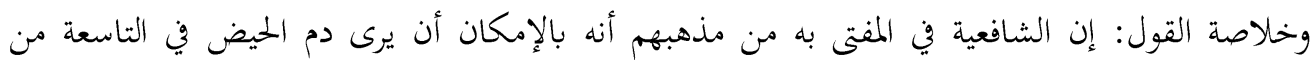

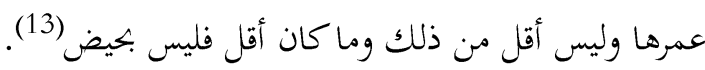
ج- الحنابلة:

أقل سن تحيض به المرأة تسع سنوات عندهم فإذا رأت الدم قبل ذلك فإنه ليس دم حيض(14). واستدلوا على ذلك بقول السيدة عائشة -رضي الله عنها: (إذا بلغت الجارية تسع سنين فهي امرأة)(15).

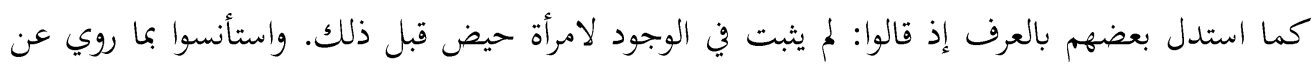
الإمام الشافعي أنه قال: (رأيت جدة لها إحدى وعشرون سنة)(16). د- المالكية:

لا يختلف رأي المالكية عن باقي الفقهاء في أن الحيض يبدأ من سن التاسعة إما في أولها وإما في وسطها على خلاف بينهم في ذلك(17).

\section{الحملاصة:}

إن معضم ما ابته إليه الفقهاء إلى أن الصبية قد ترى الدم وهو دم حيض في التاسعة من عمرها على

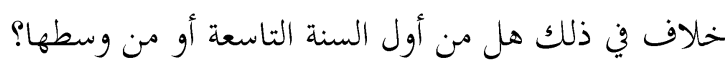

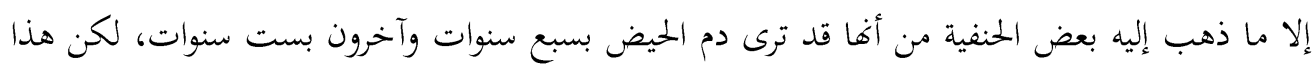
بعيد إذْ لم ييجر العرف بذلك، فما تراه من دم في هذه السن المبكرة ليس دم حيض على أرجح الأقوال.

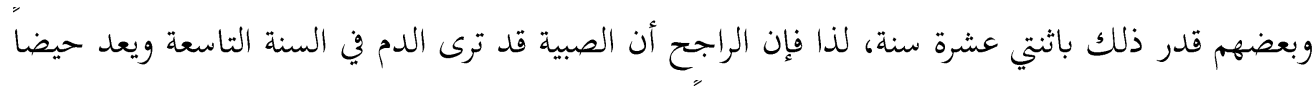

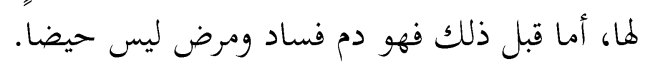

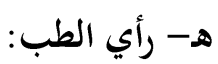

الأطباء يتجه معظمهم إلى القول: بأن السن الذي يبدأ به الحيض عند أكثر الفتيات هو ما بين العاشرة

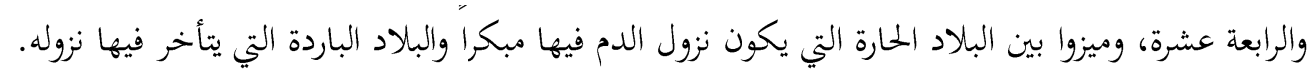

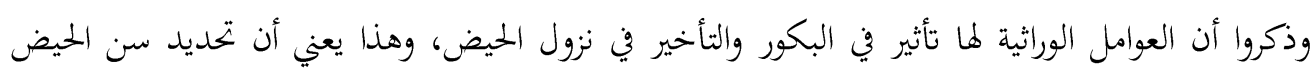
عندهم يخضع للحرارة والبرودة في المناطق كما يخضع للعوامل الوراثية.

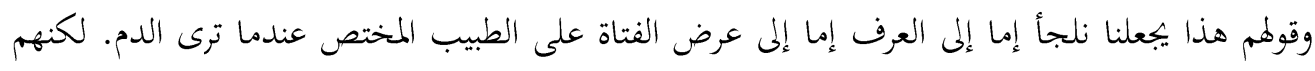
شبه متفقين إلى أنه لا نزول للحيض قبل التاسعة من العمر كما قال معظم الفقهاء(18). 
لذا فإني أرى أن الراجح لسن الميض طبا عشر سنوات فلا حيض قبله، وإن حصل شك فإن الفتاة تعرض على الطبيب المختص لتقرير ماذا كان الدم النازف منها حيضاً أو غير حيض.

ثانيا: البلوغ بالسن:

حين لا يحدث شيء من علامات البلوغ التي ذكرناها يتعين تحديد البلوغ للصبي والصبية بالسن. وهنا حصل الاختلاف في تحديد السن الذي يبلغ به الصبي أو الصبية عند الفقهاء، كما أن العلم الحديث والتحليلات المخبرية سيكون لها أثر في تحديد السن التي يبلغ لها الصبي أو تبلغ بها الصبية، لذلك سنتناول آراء الفقهاء أولا ثم نعرج على رأي الطب المعاصر في ذلك فنقول:

تحديد سن البلوغ لدى الفقهاء:

$$
\begin{aligned}
& \text { أ- الحنفية: } \\
& \text { للحنفية رأيان في تحديد سن البلوغ: }
\end{aligned}
$$

الأول: أن يبلغ الصبي أو الصبية بخمس عشرة سنة، وهو الرأي المفتى به عندهم(19). الثاني: لأبي حنيفة إذ قال: (إنما يبلغان -الصبي والصبية- بالسن إذا أتم الذكر ثماني عشرة سنة والأنتى سبع عشرة سنة)(20).

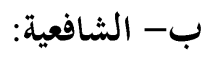

فقد ذهبوا إلى أن سن البلوغ بتمام خمس عشرة سنة للذكر والأنثى(21).

ج- الحنابلة:

فإن المذهب عندهم أن البلوغ بالسن يكصل عند بلوغ الصبي أو الصبية خمس عشرة سنة قالوا: وبهذا قال

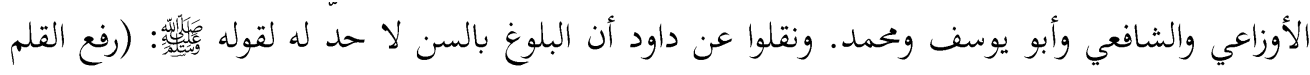
عن ثلاث: عن الصبي حتى يحتلم)(22) وإثبات البلوغ بغيره يخالف الخبر، وهو قول لمالك أيضاً(23).

د- المالكية: 20 - 20 - 20

فإهم ذهبوا إلى أن البلوغ بالسن للصبي يكون بخمس عشرة سنة، واحتجوا بحديث ابن عمر كرضي الله عنهما: إذ عرض يوم الحندق وهو ابن خمس عشرة فأجيز ولم يجز يوم أحد؛ لأنه كان ابن أربع عشرة)(24). أما الصبية فإهم يرون أها تبلغ بتسع سنين قمرية لقول عائشة -رضي الله عنها: (إذا بلغت الجارية تسع سنين فهي امرأة)(25). 


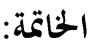

تكاد كلمة الفقهاء تتفق على أن من بلغ الخامسة عشرة من عمره فقد بلغ صبياً كان أو صبية.

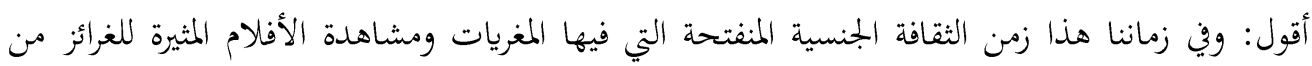

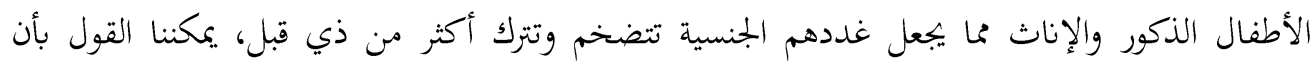
الصبي والصبية يمكن أن تكون السنة قالثانية عشرة هي سنة البلوغ. أما بعض الفقهاء فإفم ذهبو إلى قول بعيد عن المعاصرة، فقرووا أن البلوغ بإتمام ثماني عشرة سنة للذكور

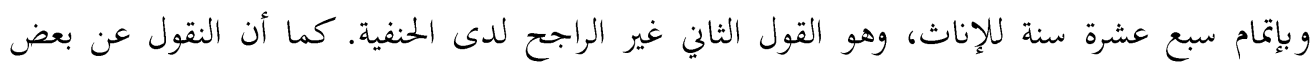

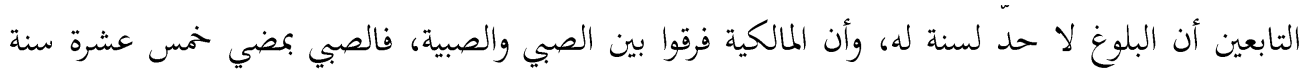
والصبية بتسع سنين، وهذا بعيد في زماننا في الصبي وقريب من الواقع في الصبية. والذي يبدو من تصريح بعضهم وتلميح الآخر: إن البيشة لها دخل في سن البلوغ؛ فني البلاد الحارة يبلغ

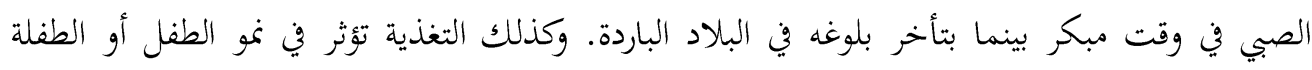

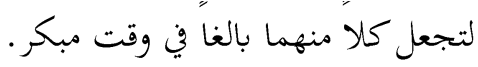
وهكذا انتشار الأفلام الجنسية والتربية الجنسية كل منها مؤثر في زماننا في تبكير سن البلوغ وربما نستطيع

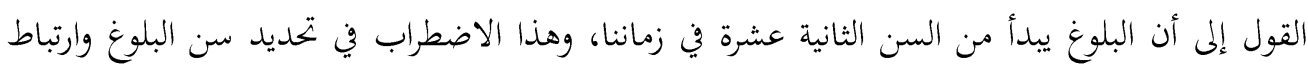
ذلك بعوامل عصرية مؤثرة نقول:

1- لابد من الرجوع على العلامات التي ذكرها الفقهاء والأطباء في تحديد البلوغ أكثر من الاعتماد

$$
\text { على السن. }
$$

2- هذا يقتضينا العودة إلى رأي الأطباء المختصين لتحديد السن عند الشك فيه اعتمادا على

$$
\text { الفحوصات المخبرية وما يقرره الأطباء الحاذقون يكون هو المعمول به. }
$$

3- رأينا أن المرجح عندي هو تحديد سن البلوغ باثنتي عشرة عاماً للأسباب التي ذكرناها. 


$$
\begin{aligned}
& \text { (7) المقنع والشرح الكبير عليه، لابن قدامة المقدسي: 355/13. المغني، لابن قدامة: 614/7. جواهر الأكليل: 618/1. }
\end{aligned}
$$

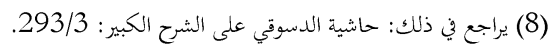

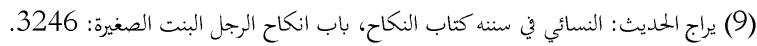

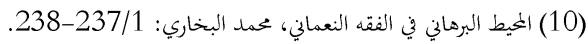

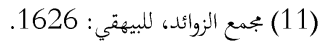

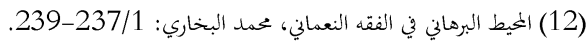

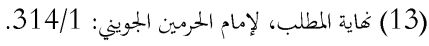

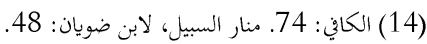

$$
\begin{aligned}
& \text { (15) (15) رواه الترمذي: } 1829 \text { (14) }
\end{aligned}
$$

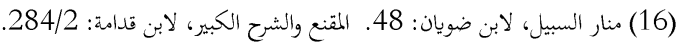

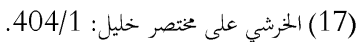

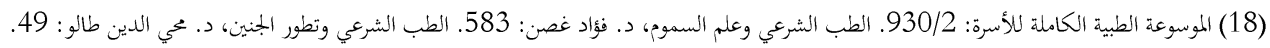

$$
\begin{aligned}
& \text { (19) رد المختار - على الدر المختار لابن عابدين: 97/5. } \\
& \text { (20) رد المتار - على الدر المختار لابن عابدين: 97/5. }
\end{aligned}
$$

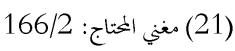$$
\text { (22) سبق تخريجه. }
$$$$
\text { (23) الشرح الكبير والانصاف عليه: 355/13-356. مراهب الجهلي الجليل: 383/3. }
$$

(24) (23) رواه مسلم. الترمذي: 1829. (25) سبق تخريجه. 